\title{
A 100-million-year old slim insectan predator with massive venom-injecting stylets - a new type of neuropteran larva from Burmese amber
}

\author{
Joachim T. Haug, Patrick Müller \& Carolin Haug
}

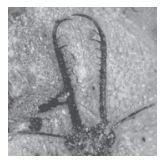

\begin{abstract}
Lacewings (Neuroptera) have highly specialised larval stages. These are predators with mouthparts modified into venom-injecting stylets. These stylets can take various forms, especially in relation to their body. Especially large stylets are known in larva of the neuropteran ingroups Osmylidae (giant lacewings or lance lacewings) and Sisyridae (spongilla flies). Here the stylets are straight, the bodies are rather slender. In the better known larvae of Myrmeleontidae (ant lions) and their relatives (e.g. owlflies, Ascalaphidae) stylets are curved and bear numerous prominent teeth. Here the stylets can also reach large sizes; the body and especially the head are relatively broad. We here describe a new type of larva from Burmese amber (100 million years old) with very prominent curved stylets, yet body and head are rather slender. Such a combination is unknown in the modern fauna. We provide a comparison with other fossil neuropteran larvae that show some similarities with the new larva. The new larva is unique in processing distinct protrusions on the trunk segments. Also the ratio of the length of the stylets $v s$. the width of the head is the highest ratio among all neuropteran larvae with curved stylets and reaches values only found in larvae with straight mandibles. We discuss possible phylogenetic systematic interpretations of the new larva and aspects of the diversity of neuropteran larvae in the Cretaceous. - Key words: Neuroptera, Myrmeleontiformia, extreme morphologies, palaeoevo-devo, fossilised ontogeny.
\end{abstract}

Haug, J.T., Müller, P. \& Haug, C. 2019. A 100-million-year old slim insectan predator with massive venom-injecting stylets - a new type of neuropteran larva from Burmese amber Bulletin of Geosciences 94(4), 431-440 (3 figures, 1 table). Czech Geological Survey, Prague. ISSN 1214-1119. Manuscript received March 18, 2019; accepted in revised form October 21, 2019; published online December 10, 2019; issued December 31, 2019.

Joachim T. Haug \& Carolin Haug, Department of Biology II, LMU Munich, Biocenter, Großhaderner Str. 2, 82152 Planegg-Martinsried, Germany \& GeoBio-Center of the LMU Munich, Richard-Wagner-Str. 10, 80333 Munich, Germany; joachim.haug@palaeo-evo-devo.info • Patrick Müller, Friedhofstr. 9, 66894 Käshofen, Germany

The entirety of the myriads of representatives of Holometabola - including bees, flies, butterflies, beetles and many more - is incredibly successful by numerous measures, be it species richness, biomass, or numbers of individuals. Part of this success has been attributed to the niche differentiation between larvae and adults. Due to this, in most cases, adult holometabolans avoid exploitation competition with their own offspring.

This has obviously led to highly specialised adults, but also to highly specialised larval forms. Caterpillars of butterflies (Lepidoptera) and sawflies (Hymenoptera) are highly efficient herbivores, transforming plant parts into insect biomass. Larvae of other groups have different ecological roles.

The larval forms of neuropterans, lacewings, are highly specialised predators (with only few exceptions). Their mouthparts form two forward oriented (prognathous) venom-injecting stylets (e.g. Aspöck et al. 2001, 2012; Beutel et al. 2010); each mandible (upper jaw) forms a stylet with an enditic protrusion (generally interpreted as the lacinia) of the next posterior mouthpart (maxilla; lower jaw).

Within the diverse subgroups of Neuroptera many different variations of this basic scheme have evolved. Many of these stylets are curved. In this way the piercing tips are facing towards each other. This arrangement is an almost ideal solution for the mechanical challenge that while piercing a prey a counteracting force is necessary; otherwise the piercing animal would simply push itself back from the prey. In counteracting mouthparts, the counteracting force is provided by the other mouthparts. This mechanical solution is not only realised in many neuropteran larvae, but also in the venom-injecting maxillipeds of most centipedes (see Haug et al. 2014 and references therein for a detailed discussion) as well as the venom-injecting chelicerae of labidognathan spiders.

Among the neuropteran larvae with curved stylets also many variations occur. The larvae of green lacewings 
(Chrysopidae; Tauber \& Tauber 2013) and brown lacewings (Hemerobiidae; Tauber \& Krakauer 1997), the aphid lions, have rather simple and slender stylets that are quite small compared to the overall body size of the larvae. The grub-like larvae of the groups Ithonidae and Polystoechotidae (Grebennikov 2004) have quite massive appearing stylets, but these are also small compared to their overall size. Much more prominent in relation to the body are the stylets of larval owlflies (Ascalaphidae; Henry 1967) and antlions (Myrmeleontidae; Badano et al. 2017). Additionally, the stylets of these (and those of their closer relatives) are armed with prominent teeth (Henry 1976, Badano et al. 2017, Haug et al. 2019a). Especially prominent are the stylets in the early, hence first stage larvae (Haug et al. 2019b). In this stage the trunk segments are quite short, the head makes up a large portion of the overall body and hence the stylets appear even longer in relation to the overall body length.

Despite the mechanical advantages of curved and counteracting stylets some groups have evolved straight mandibles. The larvae of Berothidae (Wedmann et al. 2013), Rachiberothidae (Minter 1990), Mantispidae (Dorey \& Merrit 2017), Dilaridae (Gurney 1947) and Coniopterygidae (Stürzer \& Gepp 2004) have all quite straight forward pointing stylets (slightly curved in some larvae of Mantispidae). In all these groups the stylets are rather short, in larvae of Coniopterygidae they are in fact tricky to spot at first sight (Stürzer \& Gepp 2004).

Quite the opposite accounts for the stylets of larvae of the groups Sisyridae (Weißmair 1999) and Osmylidae (Matsuno \& Yoshitomi 2016). These fully aquatic, respectively partly aquatic larvae have straight mandibles that are astonishingly large. Also here the stylets appear even more prominent in earlier stages in which the trunk segments have not yet reached their later length (Haug et al. 2019b). Recently, Haug et al. (2019b) reported a fossil neuropteran larva from the Cretaceous ( $c a .100$ million years old) with straight stylets that reach relative lengths of first stage larvae, but is at least a second stage. The oversized stylets of this "supersting" larva are accompanied by very long labial palps with numerous subdivisions. Numerous additional unusual appearing fossil neuropteran larvae from the Cretaceous (e.g. Pérez-de la Fuente et al. 2012, Wang et al. 2016, Badano et al. 2018, Liu et al. 2018, Haug et al. 2019a) provide the impression that the morphological diversity was even higher than today. In other words, there seem to have been more "experimental" morphologies in the past. Especially the Cretaceous Period seems to have been a time when many diversifying lineages of insects evolved now extinct, weird appearing morphologies.

Here we report a new neuropteran larva from Cretaceous Burmese amber. The new larva is rather unusual concerning its combination of characters and especially in the morphology of its very large stylets. We will discuss the implication of this find on our understanding of the early diversification of neuropteran larval morphologies.

\section{Material and Methods}

Material. - A single piece of amber comes from the about 100-million-year old Burmese deposits in the Hukawng Valley, Kachin State, Myanmar (Cruickshank \& Ko 2003). It was bought by one of the authors (PM) and is currently part of the collection Müller under the repository number BUB 033.

The original amber piece was first cut with a Dremel 3000. Afterwards it was polished with wet sandpaper, first grade 200 and then subsequently grades 600,1000 and 5000. Final polishing was performed with Sidol metal polish (Haug et al. 2018, 2019a, b).

Documentation methods. - The specimen was documented with composite imaging on a Keyence VHX-6000 microscope equipped with a $20-2000 \times$ objective under coaxial cross-polarised illumination (Haug et al. 2013a, 2018). Some images were recorded with different exposure times (high dynamic range, HDR; Haug et al. 2013b, 2018, 2019a, b).

Each image detail was documented as a stack, with the single images of the stack (frames) being recorded in different focal levels in the $\mathrm{z}$-axis to overcome limitations in depth of field. The frames of each stack were fused to achieve an entirely sharp image detail with the built-in software of the VHX-6000. Several adjacent stacks were recorded in $x-y$ axis to overcome limitations in the field of view. All image details were stitched to a final panorama image with the help of the built-in software of the VHX-6000 (e.g. Haug et al. 2008, 2011; Kerp \& Bomfleur 2011).

Drawings of the specimen and of comparative material were prepared in Adobe Illustrator CS2. Colour markings of specific structures were performed in Adobe Photoshop CS2.

Measurements. - Different morphological dimensions of the new specimen as well as of different fossil and extant neuropteran larvae depicted in scientific publications were measured (data set partly reused from Haug et al. 2019b). These measurements include: body length (excluding mandibles), head width, trunk width, and stylet length (direct line from proximal joint to distal tip). From the resulting values ratios were calculated (Tab. 1) as often no scales were available. The ratios were plotted into scatter plots to illustrate the rough body shape and the relative length of the stylets. 


\section{Results}

\section{Description of the specimen}

\section{The amber piece}

The specimen is preserved in a small piece of amber. The surrounding amber matrix is clear in principle, but rich in small grainy particles, making observations more difficult (Fig. 1A). This also makes the amber partly darker, which also complicates the observation. Parts of the trunk are covered by a larger non-transparent bubble surrounded by some smaller bubbles, concealing structures right beneath them. The enclosed specimen is only accessible from one side; all other directions are blocked by other particles or cracks in the amber. The only accessible
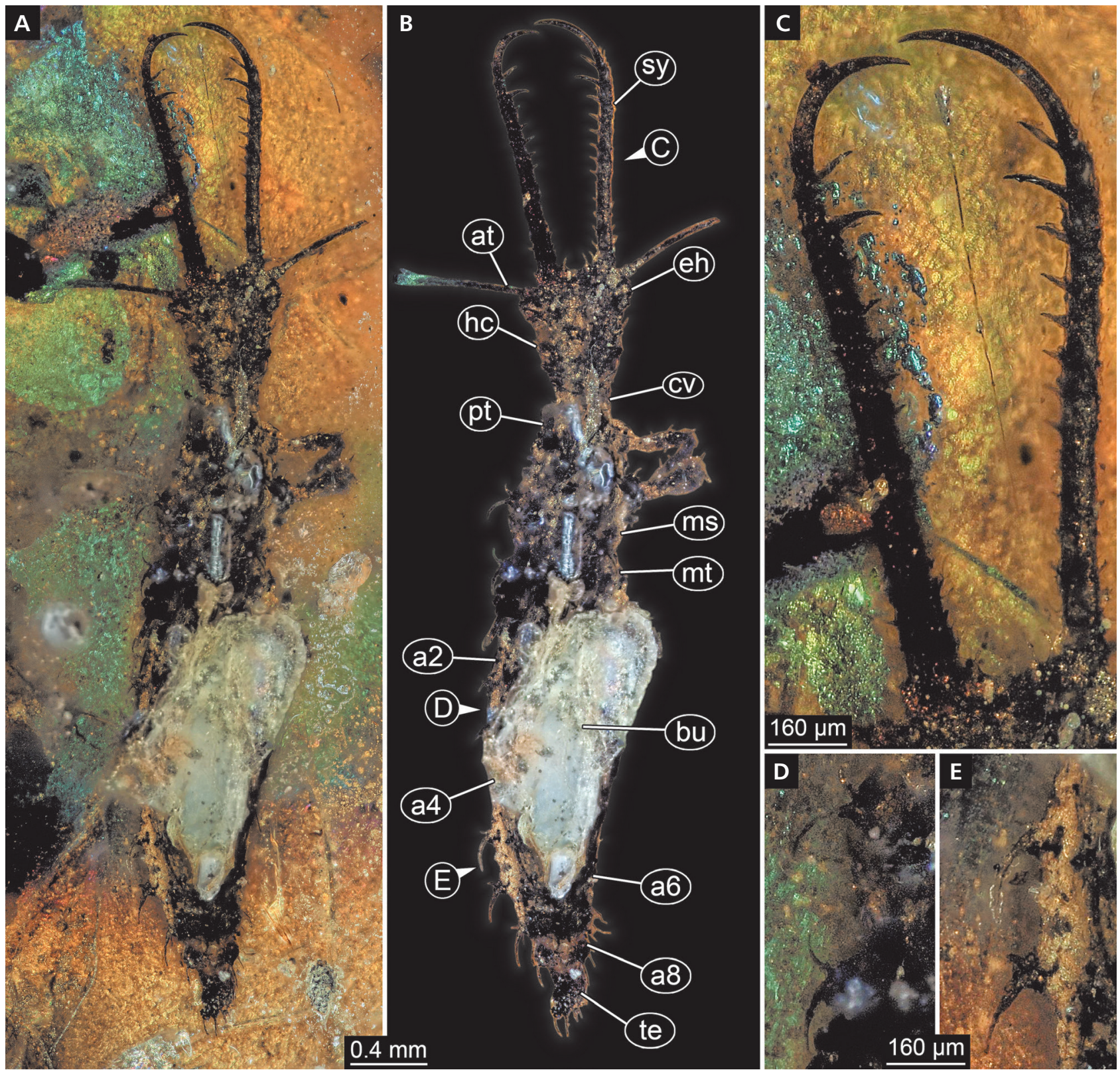

Figure 1. Neuropteran larva with massive teeth-bearing stylets. $\cdot \mathrm{A}$ - overview image, latero-dorsal view; composite image under cross-polarised light, HDR; note that the colourful background is a side-effect of the polarised light. • B - labelled version of A; background removed manually. • $\mathrm{C}$ - close-up on stylets; note the prominent teeth. $\bullet \mathrm{D}, \mathrm{E}$ - close-up on the lateral projections of the trunk segments, note the smaller forward curving spine and the larger backward curving spine; D - projections on anterior trunk segments, interpreted as meso- and metathorax; E - projections on further posterior trunk segments, interpreted as abdominal segments five and six. Abbreviations: a - abdominal segment; at - antenna; bu - bubble; $\mathrm{cv}$ - cervix; eh - eye hill; hc - head capsule; ms - mesothorax; mt - metathorax; pt - prothorax; sy - stylet; te - terminal end. 
Table 1. Ratios of measured dimensions of different neuropteran larvae for scatter plots in Fig. 2.

\begin{tabular}{|c|c|c|c|c|c|c|c|c|}
\hline Group & Species & $\begin{array}{c}\text { Larval } \\
\text { instar }\end{array}$ & Source & fig. & Origin & $\begin{array}{c}\text { body } \\
\text { length/ } \\
\text { body } \\
\text { width }\end{array}$ & $\begin{array}{c}\text { stylet } \\
\text { length/ } \\
\text { body } \\
\text { length }\end{array}$ & $\begin{array}{c}\text { stylet } \\
\text { length/ } \\
\text { head } \\
\text { width }\end{array}$ \\
\hline Ascalaphidae & Ululodes mexicana & 3 & Henry (1976) & 1 & extant & 2.11 & 0.25 & 1.25 \\
\hline Ascalaphidae & Ululodes mexicana & 1 & Henry (1976) & 4 & extant & 2.68 & 0.59 & 1.48 \\
\hline Ascalaphidae & Ascaloptynx furciger & 3 & Henry (1976) & 5 & extant & 1.97 & 0.25 & 1.11 \\
\hline Ascalaphidae & Ascaloptynx furciger & 1 & Henry (1976) & 7 & extant & 2.65 & 0.54 & 1.30 \\
\hline Ascalaphidae & Haploglenius sp. & & Badano et al. (2017) & $8 \mathrm{a}$ & extant & 2.43 & 0.21 & 1.07 \\
\hline Ascalaphidae & Puer maculatus & & Badano et al. (2017) & $8 b$ & extant & 1.76 & 0.23 & 1.00 \\
\hline Ascalaphidae & Libelloides sp. & 3 & Honomichl et al. (1998) & a-84 & extant & 2.26 & 0.26 & 0.91 \\
\hline Ascalaphidae & - & & Grimaldi \& Engel (2005) & 9,22 & extant & 2.08 & 0.30 & 1.00 \\
\hline Ascalaphidae & Ululodes sp. & & Grimaldi \& Engel (2005) & 9,24 & Dominican amber & 1.77 & 0.62 & 1.32 \\
\hline Berothidae & Podallea vasseana & 1 & Möller et al. (2006) & 7 & extant & 6.92 & 0.17 & 1.25 \\
\hline Berothidae & Lomamyia sp. & 1 & Gurney (1947) & 2 & extant & 9.22 & 0.13 & 1.38 \\
\hline Berothidae & Spermophorella sp. & 1 & Gurney (1947) & 4 & extant & 7.21 & 0.12 & 1.20 \\
\hline Berothidae & - & & Tauber et al. (2003) & 61 & extant & 7.88 & 0.04 & 1.00 \\
\hline Chrysopidae & Berchmansus adumbratus & 3 & Tauber \& Tauber (2013) & $1 \mathrm{~h}$ & extant & 4.50 & 0.09 & 0.85 \\
\hline Chrysopidae & - & & Tauber et al. (2003) & $6 \mathrm{c}$ & extant & 4.35 & 0.09 & 1.00 \\
\hline Chrysopidae & Chrysopa pallens & & Wachmann \& Saure (1997) & p. 27 bot. & extant & 3.11 & 0.14 & 1.36 \\
\hline Coniopterygidae & Conventzia pineticola & 3 & Stürzer \& Gepp (2004) & 3 & extant & 4.29 & 0.07 & 0.53 \\
\hline Coniopterygidae & Conventzia psociformis & 3 & Stürzer \& Gepp (2004) & 4 & extant & 3.24 & 0.06 & 0.54 \\
\hline Coniopterygidae & Coniopteryx sp. & 3 & Honomichl et al. (1998) & $\mathrm{c}-173$ & extant & 3.10 & 0.07 & 0.43 \\
\hline Dilaridae & Nallachius sp. & 3 & Gurney (1947) & 6 & extant & 11.42 & 0.05 & 1.17 \\
\hline Dilaridae & - & & Tauber et al. (2003) & $6 \mathrm{i}$ & extant & 10.75 & 0.04 & 1.25 \\
\hline Hemerobiidae & Mecromus vagus & 3 & Tauber \& Krakauer (1997) & 1 & extant & 5.07 & 0.03 & 0.42 \\
\hline Hemerobiidae & Hemerobius pini & & Honomichl et al. (1998) & h-10 & extant & 4.40 & 0.09 & 0.80 \\
\hline Mantispidae & Ditaxis biseriata & 1 & Dorey \& Merritt (2017) & 3 & extant & 6.25 & 0.12 & 1.09 \\
\hline Mantispidae & Mantispa syriaca & 1 & Honomichl et al. (1998) & $\mathrm{m}-10$ & extant & 6.00 & 0.06 & 0.67 \\
\hline Myrmeleontidae & - & & Tauber et al. (2003) & $5 \mathrm{~g}$ & extant & 2.52 & 0.22 & 1.04 \\
\hline Myrmeleontidae & Tricholeon relictus & & Badano et al. (2017) & $8 \mathrm{c}$ & extant & 2.54 & 0.16 & 0.88 \\
\hline Myrmeleontidae & Euroleon nostras & & Badano et al. (2017) & $8 \mathrm{~d}$ & extant & 1.94 & 0.23 & 1.23 \\
\hline Myrmeleontidae & Myrmeleon inconspicuus & 3 & Honomichl et al. (1998) & $m-60$ & extant & 2.21 & 0.19 & 1.27 \\
\hline Nemopteridae & Moranida peruviensis & & Mansell (1983) & 14 & extant & 3.21 & 0.15 & 1.33 \\
\hline Nemopteridae & Amerocroce boliviana & & Mansell (1983) & 15 & extant & 3.26 & 0.12 & 0.82 \\
\hline Nemopteridae & Veuriese bruchi & & Mansell (1983) & 25 & extant & 2.62 & 0.17 & 1.09 \\
\hline Nemopteridae & - & & Tauber et al. (2003) & $5 b$ & extant & 2.09 & 0.12 & 0.52 \\
\hline Nemopteridae & Laurhervasia setacea & 3 & Grimaldi \& Engel (2005) & 9,17 & extant & 3.55 & 0.15 & 0.85 \\
\hline Nevrorthidae & - & & Tauber et al. (2003) & 4 & extant & 9.73 & 0.08 & 1.50 \\
\hline Nevrorthidae & - & & Wichard et al. (2009) & $07.18 \mathrm{a}$ & Baltic amber & 7.90 & 0.08 & 1.44 \\
\hline Nevrorthidae & ?Rophalis relicta & 1 & Wichard et al. (2009) & $07.21 \mathrm{~b}$ & Baltic amber & 3.96 & 0.24 & 1.05 \\
\hline Nevrorthidae & Nevrorthus fallax & & Grimaldi \& Engel (2005) & 9,13 & extant & 11.65 & 0.08 & 1.60 \\
\hline unclear & Supersting & & Haug et al. (2019a) & 1,2 & Burmese amber & 3.59 & 0.46 & 2.95 \\
\hline Nymphidae & - & & Tauber et al. (2003) & $5 f$ & extant & 2.84 & 0.23 & 1.11 \\
\hline Nymphidae & - & & Tauber et al. (2003) & $5 \mathrm{e}$ & extant & 1.24 & 0.36 & 1.17 \\
\hline Osmylidae & Osmylus fulvicephalus & & Aspöck (2002) & 43 & extant & 3.79 & 0.32 & 2.00 \\
\hline Osmylidae & Osmylus fulvicephalus & & Aspöck (2002) & 45 & extant & 5.95 & 0.16 & 2.57 \\
\hline Osmylidae & - & & Tauber et al. (2003) & $6 \mathrm{~d}$ & extant & 8.29 & 0.21 & 2.40 \\
\hline Osmylidae & Osmylus fulvicephalus & & Wachmann \& Saure (1997) & p.26 bot.1. & extant & 4.86 & 0.16 & 1.60 \\
\hline Osmylidae & Osmylus fulvicephalus & 3 & Honomichl et al. (1998) & $0-30$ & extant & 5.06 & 0.23 & 1.90 \\
\hline Osmylidae & Osmylus fulvicephalus & 1 & Honomichl et al. (1998) & $0-30$ & extant & 3.92 & 0.49 & 2.30 \\
\hline Osmylidae & - & 1 & Wichard et al. (2009) & $07.04 \mathrm{a}$ & Baltic amber & 3.62 & 0.51 & 1.85 \\
\hline Osmylidae & Osmylus fulvicephalus & & Grimaldi \& Engel (2005) & 9,26 & extant & 5.06 & 0.16 & 1.36 \\
\hline Psychopsidae & - & & Tauber et al. (2003) & $5 \mathrm{a}$ & extant & 3.93 & 0.29 & 1.07 \\
\hline Sisyridae & - & & Tauber et al. (2003) & $6 \mathrm{~g}$ & extant & 3.26 & 0.34 & 3.78 \\
\hline Sisyridae & Sisyra jutlandica & 2 & Weißmair (1999) & 14 & extant & 3.80 & 0.25 & 1.90 \\
\hline Sisyridae & Sisyra jutlandica & 3 & Weißmair (1999) & 21 & extant & 3.54 & 0.25 & 3.29 \\
\hline Sisyridae & Sisyra iridipennis & 2 & Weißmair (1999) & 39 & extant & 3.88 & 0.29 & 2.70 \\
\hline Sisyridae & Sisyra iridipennis & 3 & Weißmair (1999) & 43 & extant & 3.88 & 0.26 & 3.00 \\
\hline Sisyridae & Sisyra dalii & 2 & Weißmair (1999) & 64 & extant & 3.52 & 0.19 & 1.69 \\
\hline Sisyridae & Sisyra dalii & 3 & Weißmair (1999) & 67 & extant & 2.81 & 0.28 & 2.64 \\
\hline Sisyridae & Sisyra fuscata & & Wachmann \& Saure (1997) & p.26 bot.r. & extant & 2.63 & 0.38 & 2.71 \\
\hline Sisyridae & Sisyra sp. & & Honomichl et al. (1998) & s-82 & extant & 3.69 & 0.31 & 5.00 \\
\hline Myrmeleontiformia & Superfang & & this contribution & 1 & Burmese amber & 5.07 & 0.34 & 2.35 \\
\hline Myrmeleontiformia & Macleodiella electrina & & Badano et al. (2018) & $3 a$ & Burmese amber & 8.44 & 0.28 & 1.85 \\
\hline Myrmeleontiformia & Cladofer huangi & & Badano et al. (2018) & suppl 1d & Burmese amber & 4.07 & 0.40 & 1.89 \\
\hline
\end{tabular}


direction provides access to a latero-dorsal view of the specimen.

The entire surface of the specimen appears rather dark, only in some areas the surface appears highly reflective. It seems likely that in the reflective areas the amber is not in direct contact to the surface of the fossil and therefore reflective. The entire surface appears rather rough and grainy. Although this might in part be original condition it appears likely that at least parts of this effect are also caused by interaction of original body surface and amber, i.e. a non-continuous contact between the two. The specimen might have become moved while partly decaying, this would also explain the presence of a prominent bubble above the specimen.

The very dark colour of the surface in combination with reflective areas made cross-polarised light combined with HDR an invaluable tool. Still, the specimen is more difficult to access compared to many other amber fossils.

\section{General body organisation}

The body of the specimen is organised into a discrete head (length about $0.6 \mathrm{~mm}$ ) and a trunk (length about $3.4 \mathrm{~mm}$ ) with individual segments, recognisable by folds separating the segments from each other (Fig. 1B). In total, fourteen separate units are recognisable along the trunk. The first unit after the head represents the set-off neck region, which is generally interpreted as the partly sclerotised membranous region between the head and the first trunk tergite in neuropteran larvae (Remark: the neutral term 'unit' has been used here as we can neither count 'segments' as the neck is no segment, nor sclerites as most trunk segments are not really sclerotised). The following three units represent the three thorax segments. The remaining ten units represent the eleven posterior trunk segments (most likely segment ten and elven are not separated from each other); traditionally the part of the body formed by these posterior ten units is termed abdomen (not corresponding to abdomen in other ingroups of Crustacea s.l.).

The head is slightly wider than long, roughly rounded trapezoidal in dorsal view. The anterior edge is slightly wider than the posterior one. Anterior edge with slight indent in the middle. Flanking this indent are two forward oriented setae on each side.

Postero-lateral edge with indistinct protrusions ("eye hills"). Number of possible stemmata not discernible. Posterior edge medially slightly drawn out, resulting in a gently rounded posterior edge.

Neck region more slender. Width about $60 \%$ of the width of the anterior edge of the head. About as long as wide.

Thorax segment one wider than neck, about as wide as posterior edge of head, widening posteriorly. Slightly longer (anterior-posterior dimension) than neck region.
Thorax segment two wider than preceding segment, also slightly longer. Softly bulging laterally. With a small protrusion antero-laterally forming y-shaped socket (on each side; Fig. 1D). Further anterior arm of socket pointing antero-laterally, posterior arm of socket pointing postero-laterally. Posterior arm of socket more massive than anterior one. From each socket a curved spine arises. Anterior one curving anteriorly, not being much longer than socket. Posterior one curving posteriorly being significantly longer, about $3 \times$ as long as anterior spine.

Thorax segment three wider than preceding segment, but slightly shorter. Laterally with a y-shaped socket similar to that of the preceding segment. The only difference is that the forward curving spine is slightly longer than that of the preceding segment.

Abdominal segment one rather difficult to access. Apparently similar in width to the preceding segment and of about the same length. Seems also to possess sockets and spines, arising further postero-laterally, yet the region is slightly deformed and no details can be observed.

Abdominal segment two narrower anteriorly, widening posteriorly, yet not reaching the width of the preceding segment. The y-shaped sockets present postero-laterally, smaller than those of the further anterior segments.

Abdominal segment three about as wide and long as preceding segment. The $y$-shaped sockets present posterolaterally, apparently larger than those of the further anterior segments, incompletely preserved.

Abdominal segment four difficult to access, almost completely covered by bubbles or fluid. Apparently slightly narrower than preceding segment. Presence of y-shaped sockets presumed.

Abdominal segment five narrower than preceding segments, but slightly longer. With prominent $y$-shaped sockets postero-laterally (Fig. 1E). Larger than the sockets of the further anterior segments, even those of the thoracic segments. Especially the posterior curving spine is larger.

Abdominal segment six narrower than preceding segments and about as long. With prominent y-shaped sockets postero-laterally. About as large as the sockets of the preceding segment. Dorsally with a distinct darker area in the posterior half of the dorsal surface; possibly marking a stronger sclerotised area. Possibly such areas present in the further anterior segment, yet there not accessible due to air bubbles and fluids concealing this region.

Abdominal segment seven significantly narrower and slightly shorter than preceding segment. With prominent $\mathrm{y}$-shaped sockets postero-laterally. About as large as the sockets of the preceding segment. Dorsally with a distinct darker area in the posterior half of the dorsal surface, possibly marking a stronger sclerotised area.

Abdominal segment eight narrower and shorter than preceding segment. Lateral edge with a distinct indent, postero-lateral corners gently rounded. From indent and 
rounded corners a socketed spine arising each, pointing posteriorly. Smaller than the posterior curving spines of the further anterior segments, similar in size to the forward curving spines.

Abdominal segment nine narrower than preceding segment and shorter. Partly difficult to discern details, yet with at least one spine arising laterally pointing posteriorly.

Trunk end (possibly conjoined abdominal segments $10+11)$ appears plate-like, about as wide as preceding segment but longer. With at least four spines on each side pointing posteriorly.

\section{Details of appendages}

Antenna (= antennula in other ingroups of Crustacea s.l.) arising antero-dorso-laterally from the head capsule. With one prominent proximal portion (scapus? pedicellus? or both?), being about twice as long as wide. Distal part (flagellum?) without apparent subdivisions. At least five times as long as proximal portion, slightly narrower. Unclear if fully preserved or broken at the end.

Mandibles and maxillae (upper and lower jaws) forming a pair of mandibular-maxillary stylets. Mandibular-maxillary stylets large and prominent, arising anteriorly (prognathous; Fig. 1C). About twice as long as the head capsule, about $1.2 \mathrm{~mm}$ in length. Diameter at least $3 \times$ as wide as that of the antenna. Straight in the proximal part, distinctly curved inwards in the distal fourth. Each stylet with at least eleven spines along the median edge. Proximal ones rather small. Six spines in the middle third of the stylet evenly spaced and progressively increasing in size. Most distal one of these is about as long as the maximum stylet width. Next further distal spine, penultimate one, largest of the series, prominent, twice the size of the preceding one, slightly inward curved. Most distal spine slightly smaller again, already inside the curvature of the stylet, but straight itself. No distal parts of the maxilla (maxillary palp) present.

Thoracic appendages only incompletely accessible. Coxa broad, with at least one prominent spine anterodistally. Femur more slender than coxa, widening distally; at least $2.5 \times$ as long as coxa; likewise with a prominent spine antero-distally. Tibia slender, at least as long as femur. Further appendage parts not accessible.

\section{Scatter plots}

The first scatter plot shows the general body shape (body length/maximum trunk width) on the $\mathrm{x}$-axis and the relative length of the stylets (stylet length/body length) on the y-axis (Fig. 2A). In the upper left corner of the plot are numerous larvae represented that have quite long stylets and rather round trunks. These are mostly larvae of the groups Ascalaphidae, Osmylidae, Nymphidae and Sisyridae. All these seem to be first stage larvae with rather underdeveloped trunks, i.e. the trunk segments are very short. Only the "supersting" larva (from Haug et al. 2019b) plots in the same area and is at least a stage two larva. It already has a rather long posterior trunk, emphasising how long the stylets are in this specimen. The here described specimen plots further to the right, as the body is very slender, but still far up as the stylets are rather long. Roughly in the same region plot two species from Burmese Amber that have been interpreted to represent early offshoots of the lineage of Myrmeleontiformia towards the modern forms (Badano et al. 2018).

The second scatter plot uses the same $\mathrm{x}$-axis. On the $y$-axis is the ratio of the stylet length versus the width of the head (Fig. 2B). Here all larvae of the groups Ascalaphidae and Myrmeleontidae plot close together as they appear to have a very low variability in stylet length versus head width and body length versus maximum trunk width. In the upper part of the plot we mostly find larvae of Osmylidae, Sisyridae and the "supersting" larva. All these are characterised by straight mandibles. Only three specimens with curved counteracting stylets are in the upper part of the plot: two species of the early lineage of Myrmeleontiformia reported in Badano et al. (2018) and, even further "up" in a more extreme position, the newly described larva.

\section{Discussion}

Coarse systematic interpretation. - The overall softer appearing body with three pairs of walking appendages immediately indicates that the specimen is a representative of Insecta (Hexapoda in Anglo-American literature) and a larval form of Holometabola (for a recent discussion of the term 'larva' also in Holometabola, see Haug 2018). The prominent forward oriented mouthparts (prognathous) forming two pairs of stylets indicate that this specimen is a larva of a neuropteran insect. Yet, it differs from other known neuropteran larvae in several aspects.

Uniqueness of the larva. - Already on first sight the larva looks unusual for a neuropteran larva (as discussed right above). Yet, the massive toothed stylets in combination with a rather slender body are unusual. To be quite plain, if we take an image of an owlfly larva (Ascalaphidae; e.g. Henry 1976) and artificially deform it in width to about $50 \%$, the overall body organisation becomes similar to the here described larva. In modern neuropteran larvae with similarly slender bodies the stylets are significantly shorter, as for example in larvae of Hemerobiidae (Tauber \& Krakauer 1997) and Chrysopidae (Tauber \& Tauber 
A

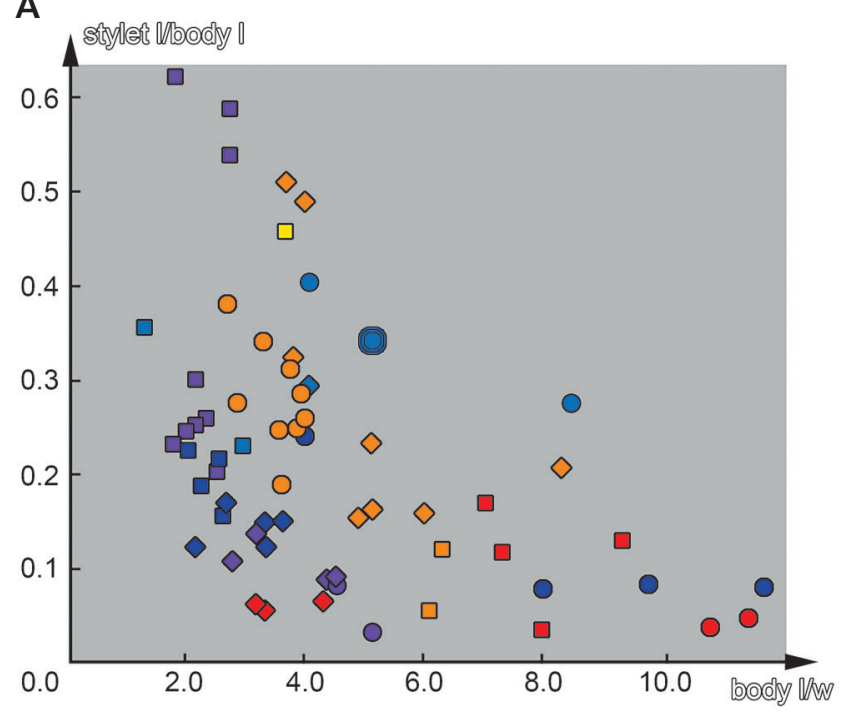

B

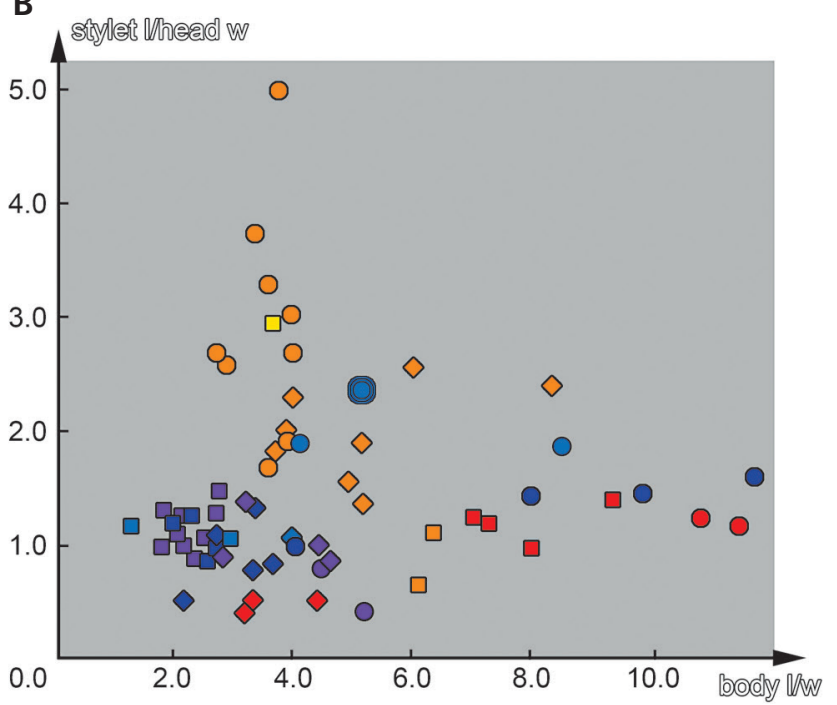

\begin{tabular}{|c|c|c|c|c|c|}
\hline $\begin{array}{l}\text { Ascalephidee } \\
\text { Chrysopidae } \\
\text { Hemerobiidee }\end{array}$ & $\begin{array}{l}\text { Myrmeleontidae } \\
\text { Nemopteridae } \\
\text { Nevrorthidae }\end{array}$ & $\begin{array}{l}\square \text { Nymphidae } \\
0 \text { Psychopsidae } \\
0 \text { early mymmeleontifomians }\end{array}$ & $\begin{array}{l}\text { (0) "Superiang" } \\
\square^{\text {"Sujpersting }}\end{array}$ & 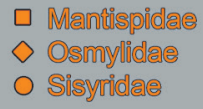 & $\begin{array}{l}\square \text { Berothidae } \\
\text { Coniopterygidae } \\
\text { Dilaridae }\end{array}$ \\
\hline
\end{tabular}

Figure 2. Scatter plots of ratios of measured dimensions of different neuropteran larvae (see Tab. 1). • A - stylet length /body length ratio vs. body length /trunk width ratio; this plot describes the general body shape. $\bullet \mathrm{B}-$ stylet length /head width ratio vs. body length /trunk width ratio; this plot illustrates the relative length of the stylets compared to the width of the head. Note the relatively eccentric position of the new larva among the larvae with curved mandibles (blue/violet tones); only larvae with straight mandibles have a larger ratio (red/orange/yellow tones).

2013), or the stylets are straight, as for example in larvae of Osmylidae (Matsuno \& Yoshitomi 2016).

Only three other fossil larval forms are roughly reminiscent to the newly described larva. Two larvae recently described by Badano et al. (2018) have a similarly slender body and large mandibles. The first larva, named Macleodiella electrina (Fig. 3A), differs from the here described larva by having shorter stylets with fewer teeth, a more elongated head capsule and neck, and by lacking lateral spine-bearing protrusions on the trunk segments (Badano et al. 2018; see also Fig. 3B).

The second larva, named Cladofer huangi (Fig. 3C), has more slender appearing stylets, also with fewer teeth; the head capsule and neck are wider. More important, the trunk segments bear long branched structures as they have been found in larvae of Chrysopidae (Wang et al. 2016). The two larvae from Badano et al. (2018) also have relatively long stylets similar to the new larva, yet the new larva is especially more extreme in the ratio of stylet length to head width. This is particularly interesting as larvae of modern species of Myrmeleontidae and Ascalaphidae seem to have a certain correlation of head width and mandible length, which is indicated by a low variability in the ratio of these values. Although speculative, this may well be coupled to their trap-jaw type catching mechanism. This could indicate that the three fossil forms did not perform their catching strike in the same manner as the modern forms do.
Already Winterton et al. (2010) pointed out that most larval lacewings with curved stylets have a rather broad spacing between them. They furthermore pointed out that many of these forms have reinforcements in their head capsules. In Myrmeleontiformia, these seem to be largely on the ventral side of the head capsule (Winterton et al. 2010). Unfortunately, this region is not accessible in the specimen at hand. It will be interesting if further specimens are found to observe this aspect in more detail.

A third larva, comparable in certain aspects to the new larva as it also has a slender trunk in combination with toothed stylets, is a recently described larva with an elongated neck similar to that of larvae of modern representatives of Crocinae (Haug et al. 2019a). Yet, this specimen differs from the new one by a distinctly more elongate neck, fewer teeth in the stylets and the absence of the spine-bearing y-shaped protrusions on the trunk segments known in the new specimen.

Summarising, the new larva differs from all known extant neuropteran larvae and also from more unusual fossil ones. It represents an extreme form in the sense that its curved stylets are extremely long in combination with a rather slender elongate body.

Systematic interpretation. - With curved and toothed mandibles the new larva could be a representative of Myrmeleontiformia. Its slender trunk could represent a plesiomorphy. Hence similar to the two species de- 


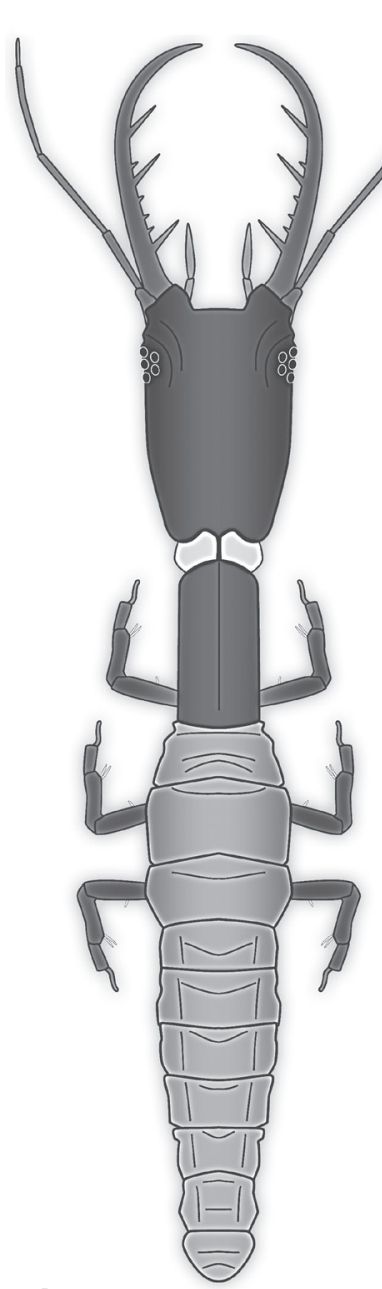

A
B

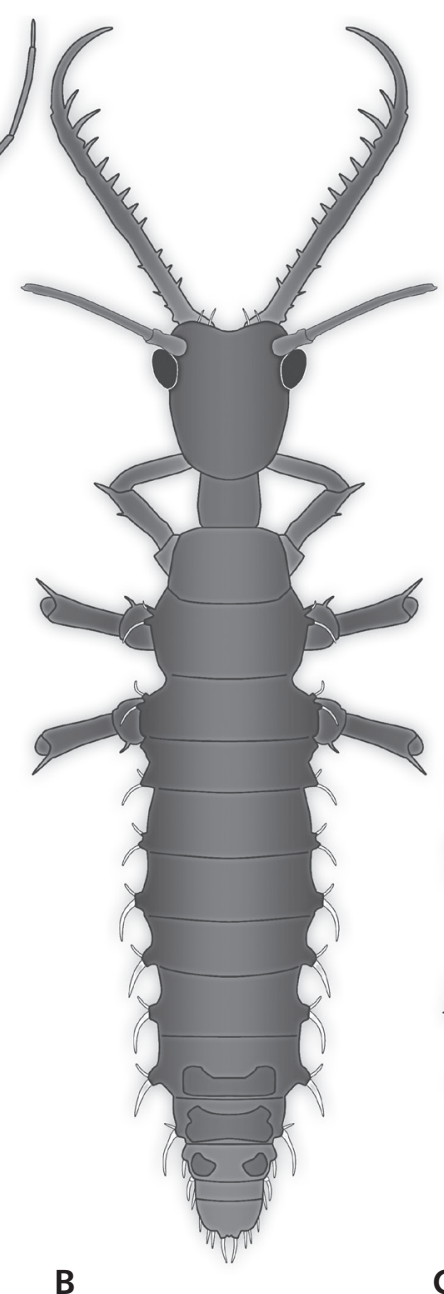

c

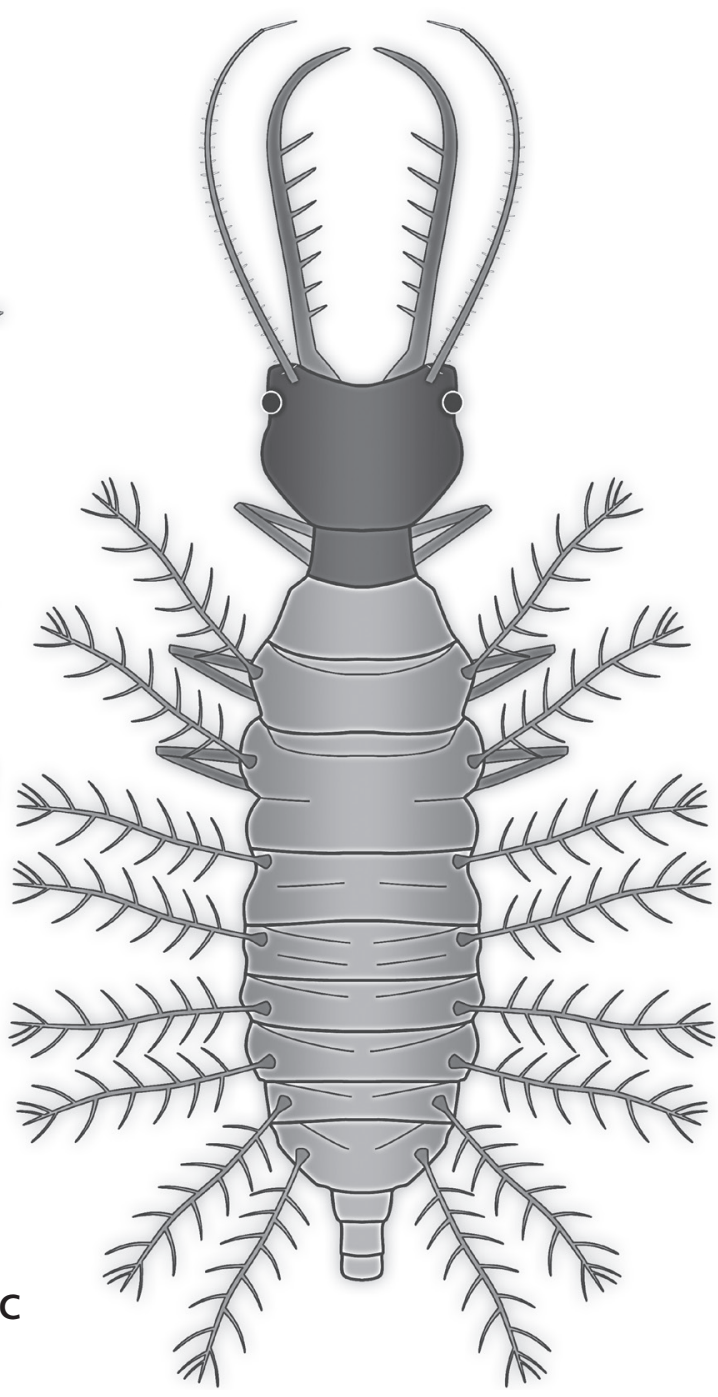

Figure 3. Restorations of three fossil neuropteran larvae with slender bodies and long curved stylets. • A - larva described as Macleodiella electrina (based on Badano et al. 2018). B - new larva, 'superfang'. • C - larva described as Cladofer huangi (based on Badano et al. 2018).

scribed by Badano et al. (2018; Macleodiella electrina and Cladofer huangi) it may be an offshoot of the early lineage of the group. Its rather slender neck could also be interpreted as an indication of a closer relationship to the long-necked specimen described by Haug et al. (2019a); yet its position is likewise uncertain. Both may still be closely related and being offshoots of the early lineage of Myrmeleontiformia or of the lineage towards Crocinae.

We refrain from erecting a species based on the specimen. While in our view the erection of species based on larvae is well possible, it demands for a proper differential diagnosis. Especially in holometabolan insects this is really challenging as connecting larvae to possibly adults is here more challenging than in many other groups. It may therefore be possible that an adult of the here described specimen has already been named, without having the chance recognising this. In order to avoid creating such a synonymy we leave the larva unnamed. To be able to properly address the specimen in future work we refer to the larva described here with the nickname 'superfang' (for this strategy see e.g. Haug et al. 2016).

Diversity of neuropteran larvae. - Already the extant fauna has quite a large variety of different types of neuropteran larvae. Still the fossil record, especially Burmese Amber, has recently provided new unexpected forms, such as the specimens described by Pérez-de la Fuente et al. (2012, 2016, 2018, 2019, 2020), Liu et al. (2016, 2018), Badano et al. (2018), and Haug et al. (2019a, b). As discussed above, these larvae seem to have in part used quite different hunting strategies in comparison to the modern forms. It seems therefore likely that back in the Cretaceous the ecological strategies of neuropteran larvae 
were more diverse than they are today, as not only the rather unusual larvae are known, but these co-occur with very modern appearing "normal" forms (e.g. Wang et al. 2016, Haug et al. 2018).

\section{Conclusions}

Two major conclusions can be drawn from these observations:

1) The Cretaceous seems to be a hotspot of diversity, combining old and new morphologies as well as experimental ones, that have not been present before and went extinct shortly afterwards.

2) Larval forms represent an important part of the ecological diversity. Traditional diversity consideration based on mere counting of species cannot account for this aspect easily. Considering diversity of larval morphologies in future diversity approaches will be an important task.

\section{Acknowledgements}

The Volkswagen Foundation kindly funds JTH with a Lichtenberg Professorship. CH was funded via the LMUexcellent Junior Researcher Fund. JTH and CH thank J.M. Starck, Munich, for continuous support. Helpful comments improving the manuscript were provided by Shaun Winterton and an anonymous reviewer. We highly appreciate the effort of all people involved in providing open access, open source and low cost software. This is LEON publication \#5.

\section{References}

AsPÖCK, H. 2002. Osmylidae: Illustrations in the early entomological literature and the discovery of early stages and clarification of the biology (Neuropterida: Neuroptera). Acta Zoologica Academiae Scientiarum Hungaricae 48(Suppl. 2), $15-34$.

Aspöck, U., Haring, E. \& Aspöck, H. 2012. The phylogeny of the Neuropterida: long lasting and current controversies and challenges (Insecta: Endopterygota). Arthropod Systematics \& Phylogeny 70(2), 119-129.

Aspöck, U., Plant, J.D. \& NemeschKal, H.L. 2001. Cladistic analysis of Neuroptera and their systematic position within Neuropterida (Insecta: Holometabola: Neuropterida: Neuroptera). Systematic Entomology 26(1), 73-86. DOI 10.1046/j.1365-3113.2001.00136.x

Badano, D., Aspöck, U., Aspöck, H. \& Cerretti, P. 2017. Phylogeny of Myrmeleontiformia based on larval morphology (Neuropterida: Neuroptera). Systematic Entomology 42(1), 94-117. DOI 10.1111/syen.12200
Badano, D., Engel, M.S., Basso, A., Wang, B. \& Cerretti, P. 2018. Diverse Cretaceous larvae reveal the evolutionary and behavioural history of antlions and lacewings. Nature Communications, 9(1), 3257. DOI 10.1038/s41467-018-05484-y

Beutel, R.G., Friedrich, F. \& Aspöck, U. 2010. The larval head of Nevrorthidae and the phylogeny of Neuroptera (Insecta). Zoological Journal of the Linnean Society 158(3), 533-562. DOI 10.1111/j.1096-3642.2009.00560.x

Cruickshank, R.D. \& Ko, K. 2003. Geology of an amber locality in the Hukawng Valley, northern Myanmar. Journal of Asian Earth Sciences 21(5), 441-455. DOI 10.1016/S1367-9120(02)00044-5

Dorey, J.B. \& Merritt, D.J. 2017. First observations on the life cycle and mass eclosion events in a mantis fly (Family Mantispidae) in the subfamily Drepanicinae. Biodiversity Data Journal 5, e21206. DOI 10.3897/BDJ.5.e21206

Grebennikov, V.V. 2004. Grub-like larvae of Neuroptera (Insecta): a morphological review of the families Ithonidae and Polystoechotidae and a description of Oliarces clara. European Journal of Entomology 101(3), 409-418. DOI 10.14411/eje.2004.056

Grimaldi, D. \& EngEL, M.S. 2005. Evolution of the Insects. 772 pp. Cambridge University Press, Hong Kong.

Gurney, A. B. 1947. Notes on Dilaridae and Berothidae, with special reference to the immature stages of the Nearctic genera (Neuroptera). Psyche: A Journal of Entomology 54(3), 145-169. DOI 10.1155/1947/78317

Haug, C., Ahyong, S.T., Wiethase, J.H., Olesen, J. \& Haug, J.T. 2016. Extreme morphologies of mantis shrimp larvae. Nauplius 24, e2016020. DOI 10.1590/2358-2936e2016020

Haug, C., Herrera-Flórez, A.F., Müller, P. \& Haug, J.T. 2019a. Cretaceous chimera - an unusual 100-million-year old neuropteran larva from the "experimental phase" of insect evolution. Palaeodiversity 12, 1-11. DOI 10.18476/pale.v12.a1

Haug, C., Shannon, K.R., Nyborg, T. \& Vega, F.J. 2013 b. Isolated mantis shrimp dactyli from the Pliocene of North Carolina and their bearing on the history of Stomatopoda. Bolétin de la Sociedad Geológica Mexicana 65, 273-284. DOI 10.18268/BSGM2013v65n2a9

HAUG, J.T. 2018. Why the term "larva" is ambiguous, or what makes a larva? Acta Zoologica, 1-22. DOI 10.1111/azo.12283

Haug, J.T., Haug, C. \& Ehrlich, M. 2008. First fossil stomatopod larva (Arthropoda: Crustacea) and a new way of documenting Solnhofen fossils (Upper Jurassic, Southern Germany). Palaeodiversity 1, 103-109.

Haug, J.T., Müller, P., \& Haug, C. 2018. The ride of the parasite: a 100 -million-year old mantis lacewing larva captured while mounting its spider host. Zoological Letters 4(1), art. 31. DOI 10.1186/s40851-018-0116-9

Haug, J.T., Müller, P. \& Haug, C. 2019b. A 100-millionyear old predator: a fossil neuropteran larva with unusually elongated mouthparts. Zoological Letters 5, art. 29.

DOI 10.1186/s40851-019-0144-0

Haug, J.T., Müller, C.H.G. \& Sombke, A. 2013a. A centipede 
nymph in Baltic amber and a new approach to document amber fossils. Organisms Diversity \& Evolution 13, 425-432. DOI 10.1007/s13127-013-0129-3

Haug, J.T., Haug, C., Kutschera, V., Mayer, G., Maas, A., Liebau, S., Castellani, C., Wolfram, U., Clarkson, E.N.K. \& WALOSZEK, D. 2011. Autofluorescence imaging, an excellent tool for comparative morphology. Journal of Microscopy 244, 259-272. DOI 10.1111/j.1365-2818.2011.03534.x

Haug, J.T., Haug, C., Schweigert, G. \& Sombke, A. 2014. The evolution of centipede venom claws - Open questions and possible answers. Arthropod Structure \& Development 43, 5-16. DOI 10.1016/j.asd.2013.10.006

Henry, C.S. 1976. Some aspects of the external morphology of larval owlflies (Neuroptera: Ascalaphidae), with particular reference to Ululodes and Ascaloptynx. Psyche: A Journal of Entomology 83(1), 1-31. DOI 10.1155/1976/71439

Honomichl, K., Bellmann, H., Jacobs, W. \& Renner, M. 1998. Biologie und Ökologie der Insekten. 3. Aufl. 638 pp. Fischer, Stuttgart.

Kerp, H. \& Bomfleur, B. 2011. Photography of plant fossils new techniques, old tricks. Review of Palaeobotany and Palynology 166, 117-151.

DOI 10.1016/j.revpalbo.2011.05.001

LiU, X., Shi, G., XIA, F., Lu, X., Wang, B. \& Engel, M.S. 2018. Liverwort mimesis in a Cretaceous lacewing larva. Current Biology 28(9), 1475-1481. DOI 10.1016/j.cub.2018.03.060

Liu, X., Zhang, W., Winterton, S.L., Breitkreuz, L.C. \& Engel, M.S. 2016. Early morphological specialization for insectspider associations in Mesozoic lacewings. Current Biology 26, 1590-1594. DOI 10.1016/j.cub.2016.04.039

Mansell, M.W. 1983. New Crocinae (Neuroptera: Nemopteridae) from South America, with descriptions of larvae. Journal of the Entomological Society of Southern Africa 46(1), 115-130.

Matsuno, S. \& Yoshitomi, H. 2016. Descriptions of three larvae of Osmylus species from Japan (Neuroptera: Osmylidae), with a proposed naming system for the larval sclerites. Zootaxa 4189(2), 348-366.

DOI 10.11646/zootaxa.4189.2.9

Minter, L.R. 1990. A comparison of the eggs and first-instar larvae of Mucroberotha vesicaria Tjeder with those of other species in the families Berothidae and Mantispidae (Insecta: Neuroptera), 115-129. In Mansell, M.W. \& Aspöck, H. (eds) Advances in Neuropterology, Proceedings of the Third International Symposium on Neuropterology. South African Department of Agricultural Development, Pretoria.

Möller, A., Minter, L.R. \& Olivier, P.A.S. 2006. Larval morphology of Podallea vasseana Navás and Podallea manselli Aspöck \& Aspöck from South Africa (Neuroptera: Berothidae). African Entomology 14(1), 1-12.

Pérez-de la Fuente, R., Delclòs, X., Peñalver, E. \& Engel, M.S. 2016. A defensive behavior and plant-insect interaction in Early Cretaceous amber-the case of the immature lacewing Hallucinochrysa diogenesi. Arthropod Structure \& Development 45, 133-139. DOI 10.1016/j.asd.2015.08.002

Pérez-de la Fuente, R., Delclòs, X., Peñalver, E., Speranza, M., Wierzchos, J., Ascaso, C. \& Engel, M.S. 2012. Early evo- lution and ecology of camouflage in insects. Proceedings of the National Academy of Sciences, 109(52), 21414-21419. DOI 10.1073/pnas.1213775110

Pérez-de la Fuente, R., Engel, M.S., Azar, D. \& Peñalver, E. 2019. The hatching mechanism of 130-million-year-old insects: an association of neonates, egg shells and egg bursters in Lebanese amber. Palaeontology 62(4), 547-559. DOI 10.1111/pala.12414

Pérez-de la Fuente, R., Engel, M.S., Delclòs, X. \& Peñalver, E. 2020. Straight-jawed lacewing larvae (Neuroptera) from Lower Cretaceous Spanish amber, with an account on the known amber diversity of neuropterid immatures. Cretaceous Research 106, art. 104200.

DOI 10.1016/j.cretres.2019.104200

Pérez-de la Fuente, R., Peñalver, E., Azar, D. \& Engel, M.S. 2018. A soil-carrying lacewing larva in Early Cretaceous Lebanese amber. Scientific Reports 8, art. 16663.

DOI 10.1038/s41598-018-34870-1

Stürzer, C. \& Gepp, J. 2004. Beiträge zur Larvalbiologie und -morphologie von Conwentzia pineticola Enderlein, 1905 und C. psociformis (Curtis, 1834) (Neuroptera: Coniopterygidae). Entomologica Austrica 11, 7-10.

TAuber, C.A. \& Krakauer, A.H. 1997. Larval characteristics and generic placement of endemic Hawaiian hemerobiids (Neuroptera). Pacific Science 51, 413-423.

TAuber, C. A. \& TAuber, M.J. 2013. An unusual chrysopid larva: identification, description, and taxonomic implications. Annals of the Entomological Society of America 106(6), 729-740. DOI 10.1603/AN13105

Tauber, C.A., Tauber, M.J. \& Albuquerque, G.S. 2003. Neuroptera (Lacewings, Antlions), 785-798. In Resh, V. \& CARdé, R. (eds) Encyclopedia of Insects. Academic Press, Burlington.

Wachmann, E. \& Saure, C. 1997. Netzflügler, Schlamm- und Kamelhalsfliegen: Beobachtung, Lebensweise. 159 pp. Naturbuch-Verlag, Augsburg.

Wang, B., Xia, F., Engel, M.S., Perrichot, V., Shi, G., Zhang, H., Chen, J., Jarzembowski, E.A., Wappler, T. \& Rust, J. 2016. Debris-carrying camouflage among diverse lineages of Cretaceous insects. Science Advances 2(6), e1501918. DOI 10.1126/sciadv.1501918

Wedmann, S., Makarkin, V.N., Weiterschan, T. \& HörnSCHEMEYER, T. 2013. First fossil larvae of Berothidae (Neuroptera) from Baltic amber, with notes on the biology and termitophily of the family. Zootaxa, 3716(2), 236-258. DOI 10.11646/zootaxa.3716.2.6

Weissmair, W. 1999. Präimaginale Stadien, Biologie und Ethologie der europäischen Sisyridae (Neuropterida: Neuroptera). Stapfia 60, 101-128.

Wichard, W., GröHn, C. \& Seredszus, F. 2009. Wasserinsekten im Baltischen Bernstein: Aquatic Insects in Baltic Amber. 336 pp. Verlag Kessel, Remagen-Oberwinter.

Winterton, S.L., Hardy, N.B. \& Wiegmann, B.M. 2010. On wings of lace: phylogeny and Bayesian divergence time estimates of Neuropterida (Insecta) based on morphological and molecular data. Systematic Entomology 35, 349-378. DOI 10.1111/j.1365-3113.2010.00521.x 